\title{
Original Result Unit
}

National Cancer Institute

\section{Source}

National Cancer Institute. Original Result Unit. NCI Thesaurus. Code C82586.

The unit of measure for the result of the test or finding as originally received or collected. 